Aletria, Belo Horizonte, v. 31, n. 1, p. 247-268, 2021

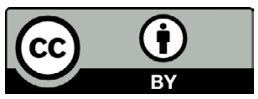

\title{
As similitudes entre os ofícios da gente miúda e as atividades próprias da gente honrada nas crônicas de Gomes Eanes de Zurara
}

\section{The Similitudes Between the Crafts of the Lower People and the Characteristic Activities of the Honored People in the Chronicles by Gomes Eanes de Zurara}

\section{Jerry Santos Guimarães}

Universidade Estadual do Sudoeste da Bahia (UESB), Vitória da Conquista, Bahia / Brasil jerryguima@gmail.com

https://orcid.org/0000-0002-7331-695X

Marcello Moreira

Universidade Estadual do Sudoeste da Bahia (UESB), Vitória da Conquista, Bahia / Brasil moreira.marcello@gmail.com

https://orcid.org/0000-0001-6827-2772

Resumo: Gomes Eanes de Zurara, segundo cronista-mor de Portugal, escreveu enquanto vigorava a longa duração da instituição retórica. Deste modo, as narrativas históricas por ele compostas eram retoricamente regradas, o que pode ser observado, por exemplo, nos usos que o cronista faz de diversos ornamentos de palavras e de pensamentos com vistas a conferir dignidade à sua elocução. Neste artigo analisamos especificamente como a similitude, um dos diversos ornamentos de sentenças prescritos por tratados de arte retórica que tinham circularidade em Portugal no século XV, é utilizada por Zurara para estabelecer paralelos entre ofícios típicos da gente miúda, geralmente tida por "baixa" e "vil", e atividades então consideradas elevadas e honradas, características de nobres e prelados. $\mathrm{O}$ engenho do cronista está justamente em encontrar semelhanças em coisas díspares, como é próprio da similitude.

Palavras-chave: escrita da história; gente miúda; literatura portuguesa; retórica; similitude; Gomes Eanes de Zurara. 


\begin{abstract}
Gomes Eanes de Zurara, second chief chronicler of Portugal, wrote throughout the long duration of the rhetoric institution. Thus, the historical narratives written by him were rhetorically regimented, and that can be observed, for instance, in the usages the chronicler makes of different word and thought ornaments with the goal of conferring dignity to his elocution. In this paper, we specifically analyze how the similitude, one of the many sentence ornaments prescribed in rhetorical treatises that circulated in Portugal in the fifteenth century, is used by Zurara to establish parallels between the crafts that were typical of the lower people, generally seen as "low" or "vile", and the activities then considered elevated and honored, that were characteristic of nobles and prelates. The wit of the author is precisely in finding similarities in disparate things, as is characteristic of the similitude.
\end{abstract}

Keywords: writing of history; lower people; Portuguese literature; rhetoric; similitude; Gomes Eanes de Zurara.

Desde os começos da monarquia em Portugal, quem não fosse da clerezia ou da nobreza era povo e situava-se dentro da categoria geral de "vilão" (MARQUES, 1974, p. 132). Dizer isso, porém, é dizer pouco ou quase nada, ainda mais quando temos em mente que o clero representava $1 \%$ e a nobreza pouco mais de $0,5 \%$ da população portuguesa no século $\mathrm{XV}$, que à época girava em torno de um milhão de habitantes. Desse modo, o terceiro estado - o dos "mantenedores", segundo as Ordenações Afonsinas $^{1}$ (liv. I, tít. LXIII, prólogo) - abarcava cerca de 98\% dos portugueses em fins da Idade Média (SOUSA, 1997, p. 327-328).

Entre os "maiores" do povo português na centúria de Quatrocentos estavam especialmente médios e grandes proprietários rurais não nobres e mercadores, os chamados homens-bons, que nas vilas e cidades monopolizavam os cargos das câmaras municipais na qualidade de cidadãos honrados. Suas posses obrigavam-nos a possuírem determinadas armas e a manterem um cavalo para servirem militarmente como cavaleiros aquantiados, anteriormente chamados de cavaleiros-vilãos (BEIRANTE, 1984, p. 44-47; MARQUES, 1974, p. 134; MONTEIRO,

\footnotetext{
${ }^{1}$ No passo acima referido as Ordenações Afonsinas, repetindo o que é dito nas Siete Partidas, de D. Alfonso X de Leão e Castela (Segunda Partida, tít. XXI, prólogo), recorrem à clássica divisão medieval da sociedade, com os seus três estados: "defensores" (os nobres), "oradores" (o clero) e "mantenedores" (os "que lavram a terra, per que os homeẽs ham de viver").
} 
1998, p. 44-58). Os restantes populares, por combaterem a pé quando convocados para a guerra, formavam o grupo dos peões, no qual se encontravam os mesteirais, ou oficiais mecânicos, e os lavradores. Era sobre eles, referidos conjuntamente como "povo miúdo" e "gente miúda", que recaía o grosso dos impostos. Abaixo de mesteirais e lavradores vinham os jornaleiros assoldadados, também chamados de obreiros, trabalhadores braçais que muitas vezes sequer ganhavam o suficiente para serem tributados (BARROS, 1896, p. 229, nota 2; GONÇALVES, 1964, p. 107; MARQUES, 1987, p. 268-276; TAVARES, 1989, p. 20).

Segundo Armindo de Sousa (1997, p. 336), no campo havia várias tarefas - lavrar, semear, ceifar, moer, panificar, podar, vindimar, pastorear, etc. -, executadas por uma só profissão, que é a do lavrador. É manifesto o contraste em relação aos mesteirais. O rei D. Duarte (1391-1438), o Eloquente, chegou a escrever que estes formariam um estado à parte, e cita como exemplos de trabalhadores das diversas "artes aprovadas e mesteres": cirurgiões, marinheiros, tangedores, armeiros, ourives "e assy dos outros que sam per tantas maneiras que nom se poderiam brevemente recontar" (D. DUARTE, 1981, p. 247). É interessante destacar que, já em meados do século XII, João de Salisbury, no seu Policraticus (2007, liv. VI, cap. 20, p. 126), quando identifica as diferentes profissões dos que atuam como os "pés" do "corpo" social, escreve que tantas são as suas distintas ocupações que os "pés" da república ultrapassam em número não apenas as oito patas de um caranguejo, mas mesmo as cem de uma centopeia, motivo pelo qual não há no mundo compilador que consiga dar conta de todos os ofícios executados por eles. Também o cronista Gomes Eanes de Zurara (c.1405-c.1474) atualizou este topos. Após discriminar uma dúzia de ofícios mecânicos que se mostraram essenciais nos preparativos para a conquista de Ceuta pelos portugueses em 1415, este autor conclui: "Quem seria aquele que, distintamente, pudesse contar os trabalhos, que havia entre aquelas gentes, cá não era algum que fosse escusado daquele encargo" (ZURARA, 1992, p. 118).

O rei D. Alfonso X de Leão e Castela (1221-1284) argumenta que as atividades realizadas por lavradores e mesteirais diferem em essência. O labor é típico dos lavradores, cujo trabalho exige que estejam constantemente em campo aberto e pelos montes, onde sofrem o frio e o calor das diferentes estações do ano. Os lavradores seriam, em decorrência disto, mais aptos a sobreviver em condições adversas. Por outro lado, a obra é o trabalho característico dos mesteirais e é 
executada em casas e lojas cobertas. Protegidos em suas oficinas das intempéries, os mesteirais "lavram ouro e prata, e fazem moedas, ou armas ou armaduras, ou os outros mesteres"2 (D. ALFONSO X, 1807, Segunda Partida, tít. XX, lei 5, tradução nossa). O que há em comum entre lavradores e mesteirais, segundo o Sábio, é que eles juntos formam o que se chama comumente de "gente miúda"3 (D. ALFONSO X, 1807, Segunda Partida, tít. X, lei 1, tradução nossa).

Mesteirais, lavradores e jornaleiros assoldadados, embora "vilãos" como os que compunham a nata do terceiro estado, eram considerados especialmente "vis" porque se sujavam ao trabalharem com as mãos (GODINHO, 1971, p. 63). Quanto mais o trabalhador se sujava ao executar o seu ofício, tanto mais vil ele era. Seguindo esta lógica, ourives e boticários, por exemplo, eram vistos como mais "limpos" e, consequentemente, mais "honrados" e "nobres" que carniceiros e ferreiros (TAVARES, 1992, p. 373). Na pena de Gomes Eanes de Zurara, contudo, não haverá uma tal diferenciação, e o oficial mecânico, independentemente do seu mester, será tratado enquanto um tipo social único, partícipe, assim como lavradores e jornaleiros assoldadados, da chusma da gente miúda. Um caso emblemático neste sentido é o dos moedeiros. Como assinala Damião Peres (1964, p. 23), os homens de Lisboa que se dedicavam ao ofício de fabricar moedas usufruíam de uma série de concessões régias que, no seu conjunto, acabavam por lhes conferir inegáveis vantagens materiais e um realce sobre os populares. Isto deu ensejo a que Armindo de Sousa (1997, p. 343-344) classificasse os moedeiros entre os "burgueses" no final da Idade Média portuguesa. A caracterização que Zurara faz dos fabricantes de moedas, contudo, coloca-os em pé de igualdade com outros oficiais mecânicos: o cronista cita-os sem qualquer distinção de importância entre calafates, açougueiros, enxerqueiros, pescadores, peixeiras, tanoeiros, alfaiates, tosadores, carpinteiros e cordoeiros (ZURARA, 1992, p. 118). Assim como o açougueiro, o mais vil dos mesteirais, o moedeiro é também gente miúda na cronística zurariana.

Ao citar Aristóteles, que diz em sua Ética a Nicômaco (VIII, 14) que o homem superior, porque virtuoso, mira a honra, enquanto o

\footnotetext{
${ }^{2}$ No original: "labran oro et plata, et facen monedas, ó armas ó armaduras, ó los otros meesteres".

${ }^{3}$ No original: "gente menuda".
} 
homem inferior prioriza o ganho, Zurara por duas vezes associa este homem inferior ao "mesteiroso" (ZURARA, 1973, p. 3; ZURARA, 1997, p. 175), uma vez ao oficial mecânico (ZURARA, 1978, p. 130), e uma última a toda a "gente mais baixa" (ZURARA, 1978, p. 136). O tipo mesteiral, independentemente do ofício que exerce, portanto, é utilizado pelo cronista como sinédoque de toda a gente miúda.

Para tornar as suas narrativas históricas verossímeis aos seus leitores e ouvintes, Gomes Eanes de Zurara deveria apresentar suas personagens de acordo com o costume e a opinião deste mesmo público, conforme ensinam antigos tratados de retórica que eram lidos no século XV português. A Retórica a Herênio (I, 16), ${ }^{4}$ por exemplo, adverte que o narrador deve pintar a personagem segundo a sua dignidade. Cícero, no seu De Inventione (I, 27, 34-36), ${ }^{5}$ acrescenta que na atualização dos caracteres devem ser observados atributos como os hábitos, a conduta, os vícios e as virtudes, segundo o decoro próprio da condição social das personagens. Deste modo, Gomes Eanes de Zurara, ao retratar os homens da gente miúda, não deixa de ressaltar alguns de seus vícios, como a cobiça desmedida pelo ganho e pelo proveito, a covardia no teatro da guerra ou a murmuração contra os superiores, por exemplo. A explicação para tais condutas vis seria a própria condição social e o "sangue baixo" da gente miúda, segundo o cronista (GUIMARÃES, 2019, p. 329-396).

Para Zurara, no entanto, não há apenas vileza entre os homens baixos do povo. Afinal, quando os desta chusma executam satisfatoriamente a sua função de "pés" que sustentam o "corpo" social por meio do seu trabalho, contribuem para o bem comum e merecem, portanto, ser elogiados. Ademais, não faltam ocasiões nas narrativas históricas zurarianas em que componentes da gente miúda se destacam como exímios e valentes guerreiros, demonstrando assim que, se lhes faltava nobreza de sangue, tinham a oferecer, ainda que à guisa de exceção, "nobreza de coração" (GUIMARÃES, 2019, p. 397-487). Pois bem, se é possível louvar a gente miúda em determinadas situações, é igualmente

\footnotetext{
${ }^{4}$ Consta no catálogo do Mosteiro de Santa Maria de Alcobaça uma cópia do século XV da Rhetorica ad Herennium, de autor desconhecido, mas até então atribuída a Cícero (FERNANDES, 2011, p. 11).

${ }^{5}$ No Mosteiro de Santa Cruz de Coimbra havia pelo menos desde o começo do século XIII uma cópia do De Inventione (FERNANDES, 2011, p. 11). Utilizamos aqui a versão em espanhol La Invención Retórica, de Salvador Núñez (CICERÓN, 1997).
} 
aceitável apontar semelhanças entre os homens desta condição e aqueles que eram considerados superiores a eles, como nobres e clérigos. E é o que Zurara faz, ancorando-se uma vez mais em preceptivas retóricas e na autoridade dos antigos.

Ensina o Anônimo da Retórica a Herênio que a elocução do discurso deve ser elegante, bem composta e digna. A elegância se consegue quando as coisas são ditas de forma correta, clara e inteligível. A boa composição implica na escolha e na ordenação adequadas das palavras. A dignidade, por fim, é obtida através da ornamentação do discurso, seja por meio de palavras, seja através de pensamentos, ou sentenças. Dentre os dezenove ornamentos de sentenças que dão dignidade à elocução elencados pelo Anônimo, interessa-nos destacar aqui a similitude (similitudo, em latim; parabolé, em grego), que consiste em extrair "alguma semelhança de coisas distintas". Além de ornar, provar, ensinar e esclarecer, a similitude pode ainda "colocar o caso diante dos olhos" do público na medida em que estabelece um paralelo no qual são identificados os elementos concordantes de coisas diferentes. O Anônimo finaliza explicando que é desnecessário que a semelhança entre as coisas comparadas seja completa, "mas é preciso que o exato ponto cotejado sustente a similitude" (Retórica a Herênio, IV, 17, 18, 46, 59-61).

Encontramos na Sagrada Escritura ${ }^{6}$ várias referências a Deus e aos seus servos enquanto artesãos. Como um artífice Deus criou os céus e a terra (Sabedoria, 13:1). Ao formar o homem a partir do barro, Ele é comparado a um oleiro (Isaías, 29:16). Após a queda do pecado original, o Senhor fez, qual alfaiate, roupas para os envergonhados Adão e Eva (Gênesis, 3:21). Desde então o acesso ao paraíso terrestre e à árvore da vida foi interditado ao primeiro casal e à sua prole por meio de querubins e de uma espada flamejante que se movia, postos a leste do Eden. Tendo criado a primeira espada, Deus apresenta-se, pois, como ferreiro e alfageme (Gênesis, 3:24). Encarnado como homem, o Filho de Deus era conhecido por seu mester de carpinteiro (Marcos, 6:3).

Atividades ligadas ao campo são também associadas a Jesus Cristo. Ao pregar, o Nazareno identificou a si mesmo como um bom pastor (João, 10:14). Neste ofício, aliás, Ele foi precedido por Moisés e por Davi (Exodo, 3:1; 1 Samuel, 16:11). E o Filho de Deus, no seu ato de evangelizar, é também lavrador que lança sementes em diferentes

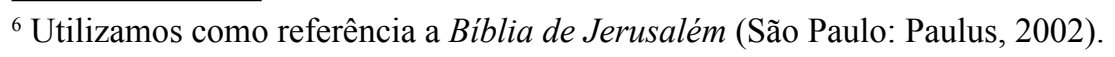


tipos de solo, segundo a parábola do semeador (Mateus, 13:1-9; Marcos, 4:3-9; Lucas, 8:4-8).

Ernst Robert Curtius (1957, p. 590-593) destaca que, além do Deus artifex, a Antiguidade conheceu o tema paralelo da Natura artifex. Em ambos os topoi temos a criação do mundo e do homem relacionados à arquitetura, à cerâmica, à ferraria, à ourivesaria, à pintura, à arte teatral e à tecelagem, dentre outros ofícios. No Timeu, por exemplo, única obra platônica conhecida no Ocidente europeu durante a Idade Média, Deus aparece como demiurgo que, qual mestre de obras e arquiteto, ordena o cosmo. Esta ideia viria a ser reverberada por Cícero, Calcídio, Boécio, Sêneca e Apuleio, bem como pela patrística. Curtius cita ainda alguns exemplos de poetas cristãos que escreveram a partir do topos do Deus artifex nos séculos XI e XII, como Marbod de Rennes, Alain de Lille e Mateus de Vendôme.

No reino português sob a Dinastia de Avis também não faltam exemplos de autores que encontraram similitudes entre ofícios característicos da gente miúda e atividades elevadas. $\mathrm{O}$ cronista Rui de Pina (1440-1522), por exemplo, toma a figura do oficial mecânico que executa a contento sua arte para metaforizar as qualidades bélicas do infante D. Henrique (1394-1460), duque de Viseu. Ao narrar a sua atuação na conquista da vila marroquina de Alcácer Ceguer, em 1458, o cronista escreve o seguinte: "O Yfante Dom Anrrique [...] naquelle Offycio [da guerra] era velho Artificial” (PINA, 1977, p. 777). Lembramos que a iniciação militar de D. Henrique se dera mais de quarenta anos antes, com a sua participação na tomada de Ceuta, em 1415. Era este infante, pois, tão experimentado na arte da guerra quanto um velho artífice em seu ofício, segundo Rui de Pina (1977, p. 777).

O infante D. Pedro (1392-1449), duque de Coimbra, e seu confessor, o frei João Verba, ao anunciarem que estão finalizando o seu Livro da Virtuosa Bemfeitoria (1981), escrevem que, quais marinheiros, sentem-se felizes por lançarem âncora sobre um porto seguro. Neste que é o último dos seis livros que compõem o tratado, os autores comparam a confecção dos cinco livros anteriores à atividade de um moleiro: no primeiro livro fizeram açude quando demonstraram "que cousa he beneffiçio" (D. PEDRO; VERBA, 1981, p. 738); no segundo ordenaram a água quando ensinaram como dar o benefício; no terceiro e quarto livros, nos quais discorreram respectivamente sobre o pedir e o receber, levaram a água até o moinho; e no quinto, ao teorizarem 
sobre o agradecimento, fizeram com que "as moos correntes moessem" (D. PEDRO; VERBA, 1981, p. 738). Deste modo, o infante e o frei comparam-se a um simples moleiro: assim como este mesteiral prepara a farinha, principal ingrediente com que se faz o pão, base da alimentação portuguesa na Idade Média, os autores, ao selecionarem de diversas fontes latinas a doutrina e traduzi-la para o vernáculo, facilitaram a formação dos nobres, público primeiro da obra (SODRÉ, 2001, p. 369).

O rei D. Afonso V (1432-1481), o Africano, em carta escrita de próprio punho a seu cronista Gomes Eanes de Zurara, datada de 22 de novembro de 1467, apresenta uma semelhança entre Deus e os homens que se ocupam das manhas do mar. O monarca agradece a Zurara, que se encontrava então no Marrocos, pela preocupação manifestada a respeito da sua saúde e, após informar que estava bem do corpo, prossegue:

como das outras cousas, em pero homem anda no mar deste mundo onde he continuamente combatido das ondas delle, en especial poys todos andamos naquella taboa depoys do primeyro naufrágio, assim que ningem se pode segurar atee que naõ chege aaquelle verdadeyro porto seguro que homem naõ pode ver senaõ depoys de sua vida, ao qual deos apraza de nos leuar quando vjr que he tempo, porque ele he marjnheyro e piloto sem o qual algum homem non pode entrar (D. AFONSO V apud ZURARA, 1978, p. 43, grifo nosso).

Assim, os homens, porque pecadores, são como náufragos agarrados a uma frágil tábua, à mercê do mar revolto que é o mundo. Isto significa dizer que a saúde de que o rei gozava quando escreveu sua missiva poderia facilmente ser "levada por uma onda". Há, contudo, a esperança de um bem-estar duradouro, que transcende o corpo. Do mesmo modo como o marinheiro e o piloto $^{7}$ experientes conseguem conduzir o barco e todos os seus ocupantes a um porto seguro mesmo debaixo de uma forte tempestade, Deus também aponta o caminho da salvação e conduz os escolhidos ao paraíso celestial.

Gomes Eanes de Zurara também extrai semelhanças entre aqueles que se dedicam aos mesteres do mar e pessoas virtuosas e de dignidade

\footnotetext{
${ }^{7}$ Os marinheiros eram basicamente homens comuns do povo. Dentre estes, aqueles que dominassem os conhecimentos técnicos necessários às manobras dos navios poderiam atuar como pilotos, muitas vezes gozando por isso da admiração dos poderosos (MARQUES, 1998, p. 204-206).
} 
superior. O cronista pondera que, assim como os miúdos do povo, os poderosos, sendo humanos e pecadores, estão no "perigoso porto" que é esta vida. Nisto os maiores e os menores se igualam. Aos "príncipes terreais", contudo, é muito mais penoso deixar esta vida, uma vez que nela se mostraram superiores à maioria dos homens. A rainha inglesa de Portugal, no entanto, foi uma exceção a este respeito, de acordo com Zurara. No passo em que se ocupa dos momentos finais de D. Filipa de Lencastre (1360-1415), então acometida de peste, o cronista escreve que a soberana conheceu que era a hora de sua morte, mas nem por isso se deixou dominar pelo terror. Ela, que havia sido tão poderosa, poderia ter se deixado seduzir por uma vida pecaminosa sem temer quem lhe repreendesse. Sua serenidade diante da morte, porém, advinha do fato de que escolhera livremente uma vida de virtudes: "Ca assim como grande navio e muito carregado há mister mais sabedores e fortes marinheiros, que outro mais pequeno, assim convém aos grandes senhores sobre os outros homens" (ZURARA, 1992, p. 161, grifo nosso). O alto estado da realeza dava à vida de $\mathrm{D}$. Filipa de Lencastre o porte de um grande, pesado e carregado navio, com todas as vantagens e obrigações aí implicados. Apesar disso, a rainha, à guisa dos mareantes mais corajosos e entendidos, soube conduzir, sempre com a ajuda de Nossa Senhora e do seu Filho, sua alma ao único e verdadeiro porto seguro, motivo pelo qual morrera bem, morrera sorrindo e morrera "santa", de acordo com Zurara.

Há semelhança ainda entre o trabalho do marinheiro e o ofício do cronista, segundo Zurara. No capítulo em que conclui a Crónica do Conde D. Pedro de Meneses, Gomes Eanes de Zurara atualiza o topos da "modéstia afetada" quando escreve que seu "fraquo emtemder", extenuado "per batimemto de comtrarias omdas", pede que ele finalize a sua obra. Esta é, sem dúvida, a mais extensa das crônicas zurarianas, e a sua escrita alongou-se por pelo menos seis anos, entre 1458 e 1464 . Concomitantemente Zurara estava coordenando a recém-iniciada reforma dos livros das chancelarias régias guardados na Torre do Tombo, onde ele ocupava o cargo de guarda-mor. Tal reforma arquivística teve início em 1459 e nela Zurara esteve envolvido até a sua morte. ${ }^{9}$ Vejamos agora as palavras com as quais o autor se despede em sua Crónica do Conde D.

\footnotetext{
${ }^{8}$ Sobre este topos remetemos a Ernst Robert Curtius (1957, p. 86-89).

${ }^{9}$ Para mais informações sobre a "Reforma de Gomes Eanes de Zurara", veja-se Judite Antonieta Gonçalves de Freitas (2009) e Saul António Gomes (2009, p. 192-194).
} 
Pedro de Meneses: "em gramde camsaço, faço termo em este capitolo e lamço amcora sobre porto, com entemção de lhe dar assesseguo per allgũus dias que não ferião taeis tempestades"10 (ZURARA, 1997, p. 718 , grifo nosso). Deste modo, assim como um experimentado marinheiro consegue chegar a um porto seguro para ancorar seu navio, mesmo afadigado após uma procela, o exausto cronista também conseguiu superar as intempéries comuns à escrita e atingiu a sua meta, a saber, a finalização de mais uma crônica encomendada pelo seu rei.

$\mathrm{O}$ escritor de história se assemelha também a um pedreiro, segundo Zurara. O cronista faz um paralelo neste sentido em duas ocasiões. A primeira delas se dá quando ele narra a chegada da frota portuguesa no Estreito de Gibraltar, em 1415, em sua expedição para tomar Ceuta. Quando os navios se aproximaram da vila cristã de Tarifa, no lado europeu, seu alcaide em nome do rei de Castela, o português Martim Fernandes Portocarrero, ${ }^{11}$ mandou seu filho, Pero Fernandes Portocarrero, levar presentes e "fazer serviço a el-Rei" de Portugal. Depois de estar por algum tempo ali, a frota portuguesa partiu rumo a Ceuta, mas uma tormenta fez os navios se dispersarem. Uma vez reunidos na Ponta dos Carneiros, o rei D. João I (1357-1433), o de Boa Memória, os infantes seus filhos e seus conselheiros deliberaram por seguir novamente em direção a Ceuta. Neste ponto Gomes Eanes de Zurara interrompe sua narrativa principal para dizer que o dito Pero Fernandes Portocarrero, filho do alcaide de Tarifa, viu aí a chance de se juntar aos portugueses para participar da tomada da cidade marroquina. Seu pai, no entanto, disse-lhe que esperasse que D. João I assentasse primeiro seu arraial diante de Ceuta, pois haveria bastante tempo para servi-lo durante o cerco que se seguiria. É então que Zurara arrazoa: "E isto escrevemos assim aqui, como nembro que fazem os pedreiros sobre a parede, para tornarmos aqui, ao depois, a fundar outra razão" (ZURARA, 1992, p. 189-209, grifo nosso). Como um pedreiro o cronista lança neste ponto

\footnotetext{
${ }^{10}$ Aqui, como em outros passos de suas crônicas, Zurara praticamente copia o que o infante D. Pedro e frei João Verba escreveram em seu Livro da Virtuosa Bemfeitoria (1981, p. 738). Sobre as apropriações feitas por Zurara deste tratado, remetemos a Joaquim de Carvalho (1949).

${ }^{11}$ Tio do conde D. Pedro de Meneses, que veio a ser o primeiro capitão de Ceuta (ZURARA, 1992, p. 190).
} 
de sua narrativa a necessária base sobre a qual retornará depois para colocar outros tijolos, dezenas de capítulos adiante.

Após a rápida conquista da praça marroquina, D. João I, em agradecimento aos serviços recebidos, mandou que se notificasse primeiramente ao alcaide de Tarifa, através do qual todo o reino de Castela seria avisado. É então que o filho deste, Pero Fernandes Portocarrero, se exaspera com o pai "porque não fora naquele feito segundo antes requerera", vendo-se assim privado de ter filhado tamanha honra (ZURARA, 1992, p. 262). Na escusa que põe na boca do pai, Martim Fernandes Portocarrero, Gomes Eanes de Zurara louva o grande feito do rei português - mas especialmente de seu filho, o infante D. Henrique, principal herói da crônica zurariana - de ter conquistado a cidade que era conhecida como "a inexpugnável" em apenas um dia:

Mas parece que Deus quis acabar o feito por outra guisa pelo qual me parece que nunca ouvi falar que cidade nem vila fosse tão em breve filhada. Cá já muitas vezes me aconteceu mandar uma meada de fiado a tingir àquela cidade e não foi tão asinha coberta de tintura, como agora foi tomada por el-rei (ZURARA, 1992, p. 262).

Se as hostes portuguesas haviam se preparado para sitiar a cidade por várias semanas, para a surpresa geral conseguiram a façanha de tomála em apenas 12 horas (DUARTE, 2015, p. 179). O cronista arremata, pois, o que sugerira anteriormente: Ceuta, a despeito do seu poderio, foi tão rapidamente conquistada pelo Rei de Boa Memória que sequer um simples tintureiro - e aqui temos um outro mesteiral utilizado como exemplo - conseguia efetuar seu serviço em tão curto espaço de tempo. Que o filho, portanto, não inculpe o pai pela grande eficiência militar dos portugueses. E assim é que Zurara, qual hábil pedreiro, levanta mais uma parede sobre a boa base narrativa por ele construída anteriormente.

Esta mesma similitude entre o cronista e o pedreiro é retomada por Gomes Eanes de Zurara em sua última crônica, no mesmo passo em que o autor também se compara a um mesteiral que se dedica ao ofício de tecer. No capítulo em que narra mais uma saída exitosa de D. Duarte de Meneses (1414-1464), primeiro capitão de Alcácer Ceguer, sobre uma aldeia moura próxima, o cronista interrompe o fluxo narrativo para fazer referência a dois acontecimentos do reino. $\mathrm{O}$ primeiro deles é o presente que o sobrinho e rival de D. Duarte de Meneses, o $3^{\circ}$. conde de 
Vila Real, ${ }^{12}$ então capitão de Ceuta, ofereceu a D. Afonso V, que àquela altura se encontrava em Torres Novas: "huma copa de prata com grande cerimonya dizendo que era feita do preço do primeyro trebuto que lhe os mouros pagarom despois que se fezerom seus uassallos" (ZURARA, 1978, p. 278). Aqui, para anunciar o segundo acontecimento, Gomes Eanes de Zurara põe-se como um tecelão: "E por que a nos perteece leuar nossa estorea ordenada como conuem. tecendo as cousas segundo os começos que ouuerom" (ZURARA, 1978, p. 278, grifo nosso). É então que o cronista informa que dois jovens fidalgos criados da casa del-rei, João Falcão ${ }^{13}$ e Diego de Barros, ${ }^{14}$ pediram licença ao Africano para combaterem no exército do rei de Fez, que então enfrentava desavenças internas no seu reino. Argumentando que D. Afonso V não tinha necessidade de seus serviços e que, devido ao seu sangue nobre, queriam obrar altos feitos, os ditos João Falcão e Diego de Barros obtiveram a autorização do seu rei. Dadas as duas notícias, Gomes Eanes de Zurara pode então voltar a narrar os feitos do conde D. Duarte de Meneses e dos nobres a seu serviço em Alcácer Ceguer, mas não sem antes fazer a seguinte ponderação:

\begin{abstract}
os quaaes leixemos estar corregendo. e nos uaamos buscar outros feitos que recontemos entanto ataa que uenha tempo e lugar em que aiamos de dizer o que paryo este mouymento por que assy como os meestre da pedrarya sobre huma pequena basa fundam huma grande e alta colluna. Assy nos entendemos sobre este pequeno começo fundar o mouymento de huum grande feito (ZURARA, 1978, p. 278, grifo nosso).
\end{abstract}

O cronista, portanto, com estas duas informações lança a necessária base sobre a qual voltará posteriormente para dar conta de novos acontecimentos que incluirão os três fidalgos - o conde de Vila Real, João Falcão e Diego de Barros - nos sucessos dos portugueses no Marrocos e que, aí sim, estarão diretamente relacionados ao conde D.

\footnotetext{
${ }^{12}$ Trata-se de D. Pedro de Meneses, neto do primeiro capitão de Ceuta de mesmo nome. Além do condado de Vila Real, este D. Pedro de Meneses recebeu de D. Afonso V o de Cantanhede, em 1479, e em 1489, já sob D. João II, foi elevado a $1^{\circ}$. marquês de Vila Real (GOMES, 2009, p. 169).

${ }^{13}$ Cavaleiro del-rei D. Afonso V, foi também senhor de direitos reais em Elvas, Évora, Olivença e Estremoz (CRUZ, 1995, p. 215, nota 42).

${ }^{14}$ Foi cavaleiro, vassalo e conselheiro del-rei D. Afonso V (CRUZ, 1995, p. 211, nota 14).
} 
Duarte de Meneses. Como um "meestre da pedrarya" não pode construir sem antes ter feito um resistente alicerce, Zurara, para tratar dos últimos acontecimentos de sua crônica e do desfecho da vida do seu protagonista como um virtuosíssimo herói - a "grande e alta colluna" - constrói neste ponto de sua narrativa o fundamento para o que viria depois.

E o que viria depois? Precisamos da ajuda de Rui de Pina para sabê-lo, já que provavelmente Zurara o contou em algum dos capítulos faltantes da Crónica do Conde D. Duarte de Meneses. ${ }^{15}$ Pina informa que, após obterem a licença de D. Afonso V, João Falcão e Diego de Barros foram a Andaluzia pedir ao duque de Medina Sidónia, com quem o rei de Fez tinha paz, cartas de apresentação. O duque castelhano, não vendo a autorização por escrito do Africano, retardou o alistamento dos dois mancebos portugueses, os quais, impacientes, partiram para Alcácer Ceguer, onde passaram a servir a D. Duarte de Meneses. Lá encontraram um antigo companheiro de cativeiro, João de Escalona, de Tarifa, e numa conversa entre si concluíram que seria possível adentrar Tânger através de "hum cano, que era nos muros da Cidade aberto e say pera fora" (PINA, 1977, p. 795). João Falcão e Diego de Barros retornaram então ao duque de Medina Sidónia, em Castela, o qual lhes informou que $\mathrm{D}$. Afonso $\mathrm{V}$ suspendera a licença para servirem no exército do rei de Fez e ordenara o retorno de ambos a Portugal. Encontrando-se com o rei, os dois nobres the comunicaram o seu plano para a conquista de Tânger, o que "no coraçam d'ElRey fez logo muyta empressam" (PINA, 1977, p. 795).

Neste ponto podemos voltar à narrativa de Gomes Eanes de Zurara, que escreve que, quando João Falcão e Diego de Barros chegaram pela segunda vez a Alcácer Ceguer enviados pelo rei para espionarem Tânger, o conde D. Duarte de Meneses desacreditou o seu plano: "Pero logo o conde disse aaquelles que nom falassem em entrada de cano que era bogerya e se cuidasse outra maneyra per que se o feito podesse acabar" (ZURARA, 1978, p. 310). No entanto, seguindo a ordem do seu rei, o capitão de Alcácer Ceguer apoiou a ida destes nobres numa missão de espionagem a Tânger. Alegre com as novas, D. Afonso V e seu irmão, o infante D. Fernando (1433-1470), decidiram ir ao Marrocos tomar aquela praça. A estratégia proposta por D. Duarte de Meneses era

\footnotetext{
${ }^{15}$ A obra original continha 156 capítulos, mas nos manuscritos que nos chegaram faltam 38 e 21 estão incompletos (KING, 1978, p. 28).
} 
que não fossem com uma grande armada para não levantarem suspeitas, mas que discretamente os portugueses entrassem em Alcácer Ceguer, de onde partiriam para Tânger. A ida do rei seria, pois, desnecessária. O capitão de Ceuta, o conde de Vila Real - o mesmo que presenteara o rei com uma "copa de prata" -, por outro lado, boicotou a estratégia do seu tio e incentivou a ida de D. Afonso V com uma poderosa frota. A 7 de novembro de 1463 o Africano e seu irmão partiram de Lisboa com suas hostes (GOMES, 2009, p. 237-239). Não foi daquela vez que Tânger foi tomada. Foi nesta passagem de D. Afonso V à África que D. Duarte de Meneses encontrou a morte defendendo o rei, em março de 1464. Daí o juízo de Gomes Eanes de Zurara: "Ca segundo eu uerdadeyramente pude saber. se o carrego soomente ficara ao conde dom Duarte. o feyto se acabara de todo" (ZURARA, 1978, p. 312). Argumenta o cronista que, como em D. Duarte de Meneses havia "grande madureza nas exucuçoões dos feitos", e como ademais vivia mais perto de Tânger, "auya della mais sabederya" (ZURARA, 1978, p. 331). A inveja do conde de Vila Real, porém, que queria aumentar a sua honra e diminuir a do seu tio, foi a raiz do mal do capitão de Alcácer Ceguer, segundo Zurara (1978, p. 331). Daí que o presente do conde de Vila Real a D. Afonso V para conquistar seu favor, bem como o pedido de João Falcão e Diego de Barros para servirem no exército do rei de Fez, narrados anteriormente pelo cronista, serviram de "pequena basa" sobre a qual Zurara construiria a "grande e alta colluna" que é o arremate de sua obra.

Tanto neste caso quanto no anterior - o desejo de Pero Fernandes Portocarrero de acompanhar as hostes de D. João I no assalto a Ceuta - há uma semelhança entre a disposição feita pelo pedreiro - primeiro a base, depois o muro, ou a coluna - e a dispositio escolhida pelo cronista para a narração dos eventos em seu discurso. Conforme definição oferecida pelo Anônimo na Retórica a Herênio (III, 16), "é pela disposição que colocamos em ordem aquilo que inventamos, para que cada coisa seja pronunciada em seu devido lugar". Ou, nas palavras de Cícero, em seu De Inventione (I, 7), a disposição serve para ordenar de forma adequada os argumentos.

O discurso enquanto totalidade pode ser dividido e subdividido em várias partes, de acordo com Heinrich Lausberg, que nos diz ainda que, para a obtenção do efeito dramático, é necessário que haja uma bipartição que contraponha o enlaçar do nó à catástrofe, a qual é o próprio desenlaçar do nó. $\mathrm{O}$ enlace, por sua vez, subdivide-se numa fase preparatória e no 
recrudescimento da situação (LAUSBERG, 2011, p. 97-99). O enlace no primeiro caso é o pedido de Pero Fernandes Portocarrero a seu pai para seguir com os portugueses em direção a Ceuta e, no segundo caso, o presente do conde de Vila Real a D. Afonso V bem como a solicitação dos mancebos fidalgos ao Africano para que pudessem combater no exército do rei de Fez. Ao enlace Gomes Eanes de Zurara chama de "base". O desenlace, por seu turno - a vitória dos portugueses em Ceuta em poucas horas e a ida de D. Afonso V ao Marrocos, o que resultou na morte do conde D. Duarte de Meneses - é referido pelo cronista como "parede" concluída e "coluna". Em ambos os casos Zurara lançou primeiro a "base", prosseguiu com a sua narrativa principal e, capítulos adiante, voltou à "base" para concluir a "construção" anteriormente iniciada. Tal artifício é utilizado mormente em narrativas em que as personagens se encontram em lugares diferentes - Pero Fernandes Portocarrero em Tarifa, D. João I na Ponta dos Carneiros e, depois, em Ceuta; e D. Afonso V, o conde de Vila Real, João Falcão e Diego de Barros em Portugal, enquanto D. Duarte de Meneses estava em Alcácer Ceguer. Isto obriga o narrador a seguir as personagens alternadamente, através de uma transitio entre uma situação e outra. É por isso que, após lançar suas "bases" e fazer uma digressio na qual que se compara a um pedreiro, Zurara retoma o fio da narrativa principal, prometendo, contudo, voltar posteriormente àquilo que acabara de anunciar, ou fundar, qual alicerce - o que de fato cumpre (LAUSBERG, 2011, p. 100).

Além do mesteiral, o lavrador é também invocado por Gomes Eanes de Zurara para estabelecer uma similitude com o nobre virtuoso, e mesmo com o rei. Conforme ressaltado por Mário Martins (1979, p. 76), quando Zurara (1992, p. 221) identifica a D. João I como "um daqueles obreiros, que o Senhor convida no Evangelho [...] para fazer seu santo serviço", o cronista está fazendo alusão à parábola dos trabalhadores na vinha, presente no Evangelho de São Mateus (20:1-16). Tais palavras foram postas por Zurara na boca de Martim Pais, capelão-mor do infante D. Henrique, numa prédica dirigida aos combatentes portugueses já diante de Ceuta, pouco antes do desembarque. Segundo a parábola, Cristo aceita e recompensa igualmente a todos os que se dispõem a trabalhar com zelo em sua vinha, não importando quão tarde tenham iniciado o seu labor. E assim é que o Rei de Boa Memória, qual obreiro na vinha pago a jornada, pode ser contado entre "os bons servidores, que verdadeiramente desejam trabalhar em alguma cousa" e que cuidadosamente buscam, 
sempre com a ajuda divina, atingir o seu fim (ZURARA, 1992, p. 222). Aqui, portanto, o cronista aponta uma louvável semelhança entre o rei e um reles trabalhador rural.

Gomes Eanes de Zurara recorre a uma outra parábola bíblica - a do semeador - para elogiar os nobres. O cronista informa que Antão Gonçalves havia sido incumbido pelo infante $\mathrm{D}$. Henrique de navegar além do Cabo Bojador com o objetivo de carregar seu navio com couro e azeite de lobos marinhos. ${ }^{16}$ Não se contentando com esta encomenda, aquele nobre e seus homens cativaram os primeiros mouros azenegues em sua própria terra. Pouco depois chegou a seu encontro Nuno Tristão, cavaleiro da casa do infante D. Henrique, "com especial mandado de seu senhor, que passasse alem do Porto da Galé, o mais longe que podesse e d'aí que trabalhasse de filhar gente por qualquer maneira que melhor podesse" (ZURARA, 1973, p. 72). Quer dizer, Antão Gonçalves, que não tinha a obrigação de fazer cativos, fê-los, no que se antecipou a Nuno Tristão. Este, acometido de uma saudável inveja, convenceu aquele a juntarem seus homens e buscarem por novos escravos, e o resultado é que conseguiram prender mais alguns mouros, que depois repartiram entre si. Nesta mesma ocasião Antão Gonçalves foi investido na ordem da cavalaria por Nuno Tristão, alcançando assim o privilégio de ter sido "o primeiro cavaleiro feito em aquelas partes" (ZURARA, 1973, p. 75). Ambos voltaram com suas cargas para Portugal, para grande alegria do infante D. Henrique. É então que Gomes Eanes de Zurara faz a seguinte comparação:

Antão Gonçalves chegou primeiro com a parte de sua presa; e depois Nuno Tristão, cujo primeiro recebimento, e depois galardão, correspondeu assim ao seu trabalho passado, como $a$ terra proveitosa com a pouca semente ao seu lavrador, a qual, por pequena parte que receba, sempre acode com grande melhoria de fruito (ZURARA, 1973, p. 80, grifo nosso).

Os dois cavaleiros e capitães, ao enfrentarem os perigos em suas viagens atlânticas a serviço do infante $\mathrm{D}$. Henrique, são assim comparados ao lavrador cujo penoso trabalho é recompensado quando suas "poucas sementes" encontram uma "terra proveitosa": em ambos os

${ }^{16}$ D. Henrique detinha o monopólio da manufatura e da venda do sabão em Portugal. O óleo dos lobos marinhos seria utilizado, pois, como matéria-prima na fabricação do sabão (RUSSELL, 2004, p. 128). 
casos os "frutos" tornam-se abundantes. Os escravos levados por Antão Gonçalves e Nuno Tristão a Portugal eram, como sabemos, valiosíssimos, e continuariam a sê-lo nos séculos subsequentes. ${ }^{17}$ Embora não seja citada diretamente, estão aqui presentes os elementos utilizados por Jesus Cristo em sua parábola do semeador. Temos, pois, um paralelo entre o lavrador arquetípico, o nobre a serviço de D. Henrique e o Filho de Deus.

Gomes Eanes de Zurara vale-se ainda da figura da atalaia para elogiar o clero. No capítulo LIII da sua Crónica da Tomada de Ceuta o autor constrói um discurso e o atribui ao frei João de Xira, confessor do rei D. João I, cujo teor é a publicação da cruzada de absolvição dos pecados dos cristãos que morressem durante o filhamento da cidade. Teria o franciscano dito aos seus ouvintes reunidos em Lagos, no Algarve, que os clérigos, no desempenho de seus ofícios, são "como atalaias no povo de Deus, para o avisar contra seus inimigos corporais" (ZURARA, 1992, p. 184). Comparação, como se vê, apropriada ao seu público, composto mormente por guerreiros. Ancorando-se no livro bíblico de Ezequiel, o discurso zurariano atribuído ao frei João de Xira prossegue argumentando que assim como as atalaias alertam as hostes para eventuais "perigos e danos", do mesmo modo os sacerdotes cristãos admoestam a sua grei contra os erros e os pecados (ZURARA, 1992, p. 184). Em assim sendo, os pastores do povo de Deus, no cumprimento de sua característica função de orar e pregar para o salvamento das almas, são similares aos peões que atuam nos bastidores da guerra enquanto atalaias, ou sentinelas, os quais, através da vigilância e de avisos, ajudam os combatentes a salvarem os seus corpos (MONTEIRO, 1998, p. 246-247).

O besteiro, guerreiro recrutado especialmente entre os mesteirais, ${ }^{18}$ é também evocado positivamente por Gomes Eanes de Zurara. O cronista de $\mathrm{D}$. Afonso $\mathrm{V}$ justifica a escrita da história como o melhor meio de fornecer ao público virtuosos exemplos a serem seguidos e emulados, segundo o que é estabelecido pelo topos historia magistra vitae

\footnotetext{
${ }^{17} \mathrm{Na}$ segunda metade do século XV o preço de um escravo africano em Lisboa oscilava entre doze e treze moedas de ouro, e até o mear da centúria seguinte o seu valor não deixaria de crescer (SAUNDERS, 1994, p. 40-48).

${ }^{18}$ As Ordenações Afonsinas (liv. I, tít. LXIX, § 29) mandam que os atiradores com a besta sejam escolhidos entre os mesteirais casados, e citam como exemplos: sapateiros, alfaiates, carpinteiros, pedreiros, almocreves, tanoeiros "e de quaeesquer outros mesteres".
} 
(GUIMARÃES, 2019, p. 139-146). Neste sentido, as crônicas oferecem modelos comportamentais que servem como alvos a serem mirados e atingidos pelos seus leitores e ouvintes. Nas palavras de Zurara:

Ca assim como no besteiro não pode ser conhecida avantagem, se antes que faça seu tiro não tem certo sinal, assim nenhum bom homem não poderia obrar perfeitamente o auto de alguma virtude, se não trouvesse ante os olhos a imagem de algum tão virtuoso, cuja proveitosa inveja lhe mostrasse o verdadeiro caminho para chegar ao fim de seu desejo (ZURARA, 1992, p. 144).

A atividade do cronista é louvável porque, por meio de sua “escritura", ele põe "ante os olhos" do seu público os modelos de virtudes a serem perseguidos. Se o autor de história consegue apresentar seus eventos e personagens com clareza e nitidez através do bom uso de procedimentos ecfrásticos, está assim oferecendo aos seus leitores e ouvintes a necessária vividez (enargeia, em grego; evidentia, em latim) para que estes possam discernir os alvos de virtudes. ${ }^{19}$ A partir de então caberá ao "bom homem" agir como um besteiro de excelente pontaria, o qual, tendo um "certo sinal" diante de si, não desperdiçará a sua seta, mas atingirá em cheio o seu alvo - ou o "fim de seu desejo", na expressão zurariana.

Lembramos que, conforme vimos páginas atrás, é para "colocar o caso diante dos olhos" do público que se deve utilizar a similitude no discurso, conforme prescreve a Retórica a Herênio. O anônimo autor deste tratado adverte ainda que qualquer pessoa "que tenha ouvido um pouco mais sobre a arte, principalmente sobre a elocução, poderá perceber as coisas ditas artificiosamente" (IV, 7). Quer dizer, esperava-se que os leitores e ouvintes do discurso fossem minimamente competentes para discernir os usos que o enunciador faz dos ornamentos de sentenças, dentre os quais nos interessa aqui a similitude. Trata-se do que João Adolfo Hansen (2006, p. 86) chama de "memória dos topoi" compartilhada entre autor e público. Deste modo, o público primeiro de Gomes Eanes de Zurara, composto especialmente pela nobreza, pela clerezia e por letrados, poderia julgar o engenho da invenção do cronista ao estabelecer paralelos entre os ofícios típicos de homens baixos do povo e as honradas atividades de eminentes membros do primeiro e do segundo estados.

${ }^{19}$ Sobre a enargeia e a ekphrasis, remetemos a João Adolfo Hansen (2006, p. 85-105). 


\section{Referências}

ALFONSO X (Don). Las siete partidas del rey D. Alfonso el Sabio, cotejadas con varios códices antiguos por la Real Academia de la Historia. t. II. Partidas Segunda y Tercera. Madrid: Imprenta Real, 1807.

BARROS, Henrique da Gama. História da administração pública em Portugal nos séculos XII a XV. t. II. Lisboa: Typograhia da Academia Real das Sciencias, 1896.

BEIRANTE, Maria Ângela. As estruturas sociais em Fernão Lopes. Lisboa: Livros Horizonte, 1984.

BÍBLIA de Jerusalém. Nova edição, revista e ampliada. Tradução do texto em língua portuguesa diretamente dos originais. Tradução de Euclides Martins Balancin et al. São Paulo: Paulus, 2002.

CARVALHO, Joaquim de. Estudos sobre a cultura portuguesa do século $X V$. v. I. Coimbra: Editora da Universidade de Coimbra, 1949.

CICERÓN. La invención retórica. Introducción, traducción y notas de Salvador Núñez. Madrid: Editorial Gredos, 1997.

CRUZ, Abel dos Santos. A nobreza portuguesa no Marrocos no século $X V$ : (1415-1464). 325 f. Dissertação (Mestrado em História Medieval) Faculdade de Letras, Universidade do Porto, Porto, 1995.

CURTIUS, Ernst Robert. Literatura européia e Idade Média latina. Tradução de Teodoro Cabral e Paulo Rónai. Rio de Janeiro: Ministério da Educação e Cultura / Instituto Nacional do Livro, 1957.

DUARTE (Dom). Leal conselheiro o qual fez Dom Eduarte rey de Portugal e do Algarve e Senhor de Cepta. In: OBRAS dos príncipes de Avis. Introdução e revisão de M. Lopes de Almeida. Porto: Lello \& Irmão Editores, 1981. p. 233-442.

DUARTE, Luís Miguel. Ceuta, 1415: 600 anos depois. Lisboa: Livros Horizonte, 2015.

FERNANDES, R. M. Rosado. Breve introdução aos estudos retóricos em Portugal. In: LAUSBERG, Heinrich. Elementos de retórica literária. 6. ed. Tradução, prefácio e aditamentos de R. M. Rosado Fernandes. Lisboa: Fundação Calouste Gulbenkian, 2011. p. 13-32. 
FREITAS, Judite Antonieta Gonçalves de. Chancelarias régias quatrocentistas portuguesas: produção, manuscrita e aproximação político-diplomática. Revista da Faculdade de Ciências Humanas e Sociais, Porto, 6, p. 136-150, 2009.

GODINHO, Vitorino Magalhães. A estrutura da antiga sociedade portuguesa. Lisboa: Editora Arcádia, 1971.

GOMES, Saul António. D. Afonso V: o Africano. Lisboa: Círculo de Leitores/Temas e Debates, 2009.

GONÇALVES, Iria. Pedidos e empréstimos públicos em Portugal durante a Idade Média. Lisboa: Centro de Estudos Fiscais da DirecçãoGeral das Contribuições e Impostos/Ministério das Finanças, 1964.

GUIMARÃES, Jerry Santos. "De qualquer outro do povo escrevera seu feito, se o achava em merecimento": memória e esquecimento da "gente miúda" nas crônicas de Gomes Eanes de Zurara. Orientador: Prof. Dr. Marcello Moreira. 2019. 527 f. Tese (Doutorado em Memória: Linguagem e Sociedade) - Programa de Pós-Graduação em Memória: Linguagem e Sociedade, Universidade Estadual do Sudoeste da Bahia, Vitória da Conquista, 2019. Disponível em: https://bit.ly/3hxlHVo. Acesso em: 09 mar. 2021.

HANSEN, João Adolfo. Categorias epidíticas da ekphrasis. Revista Usp, São Paulo, n. 71, p. 85-105, set.-nov. 2006. DOI: https://doi.org/10.11606/ issn.2316-9036.v0i71p85-105.

JOHN OF SALISBURY. Policraticus: of the frivolities of courtiers and the footprints of philosophers. Edited and translated by Cary J. Nederman. Cambridge: Cambridge University Press, 2007.

KING, Larry. Introdução. In: ZURARA, Gomes Eanes de. Crónica do conde D. Duarte de Meneses. Edição diplomática de Larry King. Lisboa: Universidade Nova de Lisboa, 1978. p. 21-40.

LAUSBERG, Heinrich. Elementos de retórica literária. 6. ed. Tradução, prefácio e aditamentos de R. M. Rosado Fernandes. Lisboa: Fundação Calouste Gulbenkian, 2011.

MARQUES, A. H. de Oliveira. A expansão no Atlântico. In: SERRÃO, Joel; MARQUES, A. H. de Oliveira (dir.). Nova história da expansão portuguesa. v. II. A expansão quatrocentista. Coordenação de A. H. de Oliveira Marques. Lisboa: Editorial Estampa, 1998. p. 9-233. 
MARQUES, A. H. de Oliveira. Portugal na crise dos séculos XIV e XV. Lisboa: Editorial Presença, 1987.

MARQUES, A. H. de Oliveira. A sociedade medieval portuguesa: aspectos da vida cotidiana. 3. ed. Lisboa: Livraria Sá da Costa Editora, 1974.

MARTINS, Mário. A Bíblia na literatura medieval portuguesa. Lisboa: ICALP, 1979. (Biblioteca Breve/Volume 35).

MONTEIRO, João Gouveia. A guerra em Portugal nos finais da Idade Média. Lisboa: Editorial Notícias, 1998.

PEDRO (Infante Dom); VERBA, João (Frei). O livro da virtuosa bemfeitoria do infante Dom Pedro. In: OBRAS dos príncipes de Avis. Introdução e revisão de M. Lopes de Almeida. Porto: Lello \& Irmão Editores, 1981. p. 525-763.

PERES, Damião. História dos moedeiros de Lisboa como classe privilegiada. t. I. Privilégios. Lisboa: Academia Portuguesa de História, 1964.

PINA, Rui de. Chronica do senhor rey D. Affonso V. In: PINA, Rui de. Crónicas de Rui de Pina. Introdução e revisão de M. Lopes de Almeida. Porto: Lello \& Irmão Editores, 1977. p. 576-881.

RETÓRICA a Herênio. Tradução e introdução de Ana Paula Celestino Faria e Adriana Seabra. São Paulo: Hedra, 2005.

RUSSELL, Peter. Henrique, o Navegador. Tradução de Ana Carvalho. Lisboa: Livros Horizonte, 2004.

SAUNDERS, A. C. de C. M. História social dos escravos e libertos negros em Portugal (1441-1555). Lisboa: Imprensa Nacional/Casa da Moeda, 1994.

SODRÉ, Paulo Roberto. A vertuosa compilaçom do infante D. Pedro e frei João Verba. In: MONGELLI, Lênia Márcia (coord.). A literatura doutrinária na Corte de Avis. São Paulo: Martins Fontes, 2001. p. 307384.

SOUSA, Armindo de. 1325-1480. In: MATTOSO, José (dir. e coord.). História de Portugal. v. II. A monarquia feudal (1096-1480). Lisboa: Editorial Estampa, 1997. p. 236-466. 
TAVARES, Maria José Ferro. História de Portugal medievo: economia e sociedade. Lisboa: Universidade Aberta, 1992.

TAVARES, Maria José Pimenta Ferro. Pobreza e morte em Portugal na Idade Média. Lisboa: Editorial Presença, 1989.

ZURARA, Gomes Eanes de. Crónica da tomada de Ceuta. Introdução e notas de Reis Brasil. Lisboa: Publicações Europa-América, 1992.

ZURARA, Gomes Eanes de. Crónica de Guiné. Introdução, novas anotações e glossário de José de Bragança. Barcelos: Livraria Civilização Editora, 1973.

ZURARA, Gomes Eanes de. Crónica do conde D. Duarte de Meneses. Edição diplomática de Larry King. Lisboa: Universidade Nova de Lisboa, 1978.

ZURARA, Gomes Eanes de. Crónica do conde D. Pedro de Meneses. Edição e estudo de Maria Teresa Brocardo. Braga: Fundação Calouste Gulbenkian/Junta Nacional de Investigação Científica e Tecnológica, 1997.

Recebido em: 17 de junho de 2020 Aprovado em: 23 de fevereiro de 2021 